SAE TECHNICAL

2007-24-0065 PAPER SERIES

\title{
Combustion Characteristics of Hydrogen-Natural Gas Mixtures in Passenger Car Engines
}

P. Dimopoulos

Empa, Swiss Federal Laboratories for Materials Testing and Research, Laboratory for I.C. Engines

K. Boulouchos

Aerothermochemistry and Combustion Systems Laboratory ETH, Swiss Federal Institute of Technology

C. Rechsteiner

Fiat Powertrain Technologies, Iveco Motorenforschung AG

P. Soltic, R. Hotz

Empa, Swiss Federal Laboratories for Materials Testing and Research, Laboratory for I.C. Engines 


\title{
Combustion Characteristics of Hydrogen-Natural Gas Mixtures in Passenger Car Engines
}

\author{
P. Dimopoulos \\ Empa, Swiss Federal Laboratories for Materials Testing and Research, Laboratory for I.C. Engines \\ K. Boulouchos \\ Aerothermochemistry and Combustion Systems Laboratory ETH, Swiss Federal Institute of Technology \\ C. Rechsteiner \\ Fiat Powertrain Technologies, Iveco Motorenforschung AG \\ P. Soltic and R. Hotz \\ Empa, Swiss Federal Laboratories for Materials Testing and Research, Laboratory for I.C. Engines
}

Copyright @ 2007 SAE International

\begin{abstract}
The presented concept in this study consists of a state of the art passenger car natural-gas engine fired by different hydrogen $\left(\mathrm{H}_{2}\right)$ and compressed-natural-gas (CNG) fuel blends. The hydrogen content in the fuel was varied among 5 and $15 \mathrm{vol} \%$ corresponding to $0.6-2.1$ mass $\%$, while comparisons include also engine operation on pure CNG.

Increasing hydrogen content of the fuel accelerated combustion leading to modest efficiency improvements. Combustion analysis showed that the increasing burning rates mainly affected the initial combustion phase (duration for $5 \%$ mass fraction burned).

With optimal combinations of spark timing and EGR rate the achievements are additional efficiency increase with substantially lower engine-out $\mathrm{NO}_{x}$ while total unburned hydrocarbons or CO-engine-out emissions are not affected.

Investigations using Design of Experiments (DoE) algorithms provided a comprehensive picture of the entire parameter space. The investigations showed two fuel consumption optimal combustion domains: Low EGR and late spark timing with associated high engine-out $\mathrm{NO}_{\mathrm{x}}$ emissions as well as high EGR and early spark timing with very low engine-out $\mathrm{NO}_{\mathrm{x}}$.
\end{abstract}

\section{INTRODUCTION}

A significant reduction of $\mathrm{CO}_{2}$ emissions in the mobility sector is a major challenge for the next decades. In combination with efficient powertrain technologies, the potential of natural-gas is excellent for a comparably high as well as cost effective reduction in $\mathrm{CO}_{2}$ and toxic emissions in the near future.

In the recent past our laboratories have demonstrated the potential of a natural-gas optimised engine vehicle with the Clean Engine Vehicle (CEV) project. The vehicle used was a production line small sedan (model year 2000 ) with a curb weight of $1020 \mathrm{~kg}$. The achieved goal was $30 \%$ lower $\mathrm{CO}_{2}$ emissions than the gasoline vehicle while staying in compliance with Euro-4 as well as SULEV emission limits, [1]. These low pollutant levels have been reached mainly through the use of Three Way Catalysts (TWCs) and improved engine management functions. Vehicle performances have been improved in respect to the level of the gasoline version. Therefore the engine compression ratio was increased while a specially developed turbocharging strategy was implemented.

The objectives of the most recent approaches are further reduction of $\mathrm{CO}_{2}$ emissions while meeting the most stringent emissions standards and reducing system costs, mainly by reducing the amount of precious metals in the catalyst. One effective method for solving the problem of the slow-burning velocity of natural gas is to mix the natural gas with a fuel that possesses fast burning characteristics. Hydrogen is regarded as the best gaseous candidate because of its very high burning velocity. Possible combinations with high EGR have the 
potential to lead to improved thermal efficiencies with less pollutant formation.

Several studies, to mention [2], [3], [4] and [5], showed that addition of reformer gas (mainly consisting of $\mathrm{H}_{2}$ and $\mathrm{CO}$ ) to gasoline allows stable operation of the engine under extreme conditions, such as ultra-lean air-fuel mixtures, or very high rates of exhaust gas recirculation. In addition they revealed crucial advantages during cold start and warm up, reducing substantially unburned hydrocarbons. The benefits found have been identified on the impact of the hydrogen compound of the fuel on the combustion process, derived from its extremely high reactivity. The hydrogen molecules promptly dissociate, providing active radicals that speed up the methane dissociation. That makes the ignition of the mixture easier, and so the flame front propagation towards the chamber walls, even in presence of inert gas (EGR), ([2], [3], [4] and [5]).

In parallel, some research was performed in respect to the use of $\mathrm{H}_{2}$-CNG mixtures. In [6] a comprehensive overview of the results known so far is provided. The reported results indicate decreased $\mathrm{HC}$ and $\mathrm{CO}$, increased $\mathrm{NO}_{\mathrm{x}}$ emissions and increased fuel conversion efficiency, only at modest substitution levels of the CNG by hydrogen. In addition all reported results demonstrated the ability to achieve leaner combustion as the amount of hydrogen increases. The studies referred to by [6] have been performed on a bright variety of engines, most of them being research engines while some of them derived from gasoline production engines.

In [7] the studies mainly focussed on full load behaviour of a 0.61 It displacement, one-cylinder, low compression ratio research engine. The thermal efficiency reported for stoichiometric operation slightly increases with low hydrogen substitution and decreases after the hydrogen content of the fuel surpasses approx. the $20 \mathrm{vol} \%$. Possible explanation could be the higher in-cylinder temperature causing higher wall heat losses as well as the knock-limited spark timing. In [8] similar observations have been reported. The full load indicated power output of the engine increases with increasing hydrogen substitution as long as the substitution lies below roughly $20 \mathrm{vol} \%$. Further increase of the hydrogen content of the fuel leads to decreasing power output. This behaviour was more pronounced at high compression ratios. The authors believe that the explanation therefore lies rather on the lower volumetric heating value of the fuel blend. Nevertheless different studies agree in the conclusion of [6] that for stoichiometric combustion only moderate hydrogen enrichment of natural gas gives the most favourable engine operation, while too low hydrogen contents do not make enough use of the potential of hydrogen and too high hydrogen contents in the fuel have combustion characteristics less suitable for usual combustion chambers.

In [9] a systematic investigation has been performed of the emissions at different engine speeds, loads as well as lean mixtures. Compared have been the engine emissions with pure CNG vs. $15 \mathrm{vol} \%$ hydrogen-CNG blend. The results obtained demonstrated the potential of the methane and hydrogen mixture reducing the exhaust concentrations of regulated pollutants while increasing the efficiency. The engine used was a modified gasoline production engine with a quite low compression ration of 8.8:1. Also a former gasoline engine modified for natural gas operation with a similar low compression ratio was used in [10]. Again the emissions have been the focus, while a series of fuel blends have been tested. Reaping the benefits of lean operation and keeping the emissions in accordance to the regulation without expensive aftertreatment devices resulted in a difficult task. To reduce hydrocarbon emissions $\lambda$ had to be less than 1.3 while $\mathrm{NO}_{\mathrm{x}}$ reduction required $\lambda$ values of at least 1.5 .

While in [11] the effects of hydrogen addition to CNG have been evaluated for a stationary power generation unit, in [12] the hydrogen addition effects have been studied for homogeneous charge compression ignited $(\mathrm{HCCl})$ engine operation. [13] focussed in the direct injection of the fuel mixture in the cylinder where the effects of injection beginning and different fuel compositions have been assessed.

However, very little information is available concerning combustion analysis and characteristics of hydrogen CNG fuel blends in specific optimised current state natural gas engines. Even more scarce is information concerning the combustion of $\mathrm{H}_{2}$-CNG blends with high EGR. To our knowledge the only study available is [14]. Nevertheless the focus of [14] was combustion stabilisation with varying $\mathrm{H}_{2}$ fuel contents as well as EGR rates. On the other side, some detailed information concerning combustion of pure $\mathrm{H}_{2}$ with EGR is available, [15].

In a first step [16] we have examined the effects of EGR in the optimised gas engine (as described in the next section) with pure CNG fuel. Only a modest part of the EGR benefits could be reaped, due to the "slow" pancake shaped combustion chamber and the absence of any special charge motion within the cylinder. In [17] we have performed first investigations with $\mathrm{H}_{2}$-CNG fuel blends with promising results. In [18] preliminary results have been published confronting efficiency and emissions at one engine speed and load fuelled by pure CNG and two $\mathrm{H}_{2}$-CNG fuel blends. The amount of EGR and the spark timing have been obtained for optimal fuel conversion efficiency. In the low load examined, the combination of the optimal spark timing, EGR amount and hydrogen content of the fuel resulted in an efficiency increase of $3 \%$, engine-out NOx decrease of approx. $50 \%$, without affecting $\mathrm{CO}$ and unburned hydrocarbons.

Nevertheless the interpretation of the combustion analysis results demanded additional information concerning more engine speeds and loads and in particular the indepth analysis of $\mathrm{H}_{2}$-CNG blend combustion in absence of EGR. In the present paper it is our attempt to close the gap and provide aside from more understanding of 
$\mathrm{H}_{2}$-CNG mixtures combustion, some additional insights for combustion of $\mathrm{H}_{2}$-CNG in combination with EGR.

\section{ENGINE AND FUELS}

\section{ENGINE}

The original engine was a Volkswagen Polo (a typical European small sedan, MY2000) naturally aspirated 4 cylinder gasoline engine with a displacement of 1.Olitre, a power output of $37 \mathrm{~kW}$ at $5000 \mathrm{RPM}$ and $86 \mathrm{Nm}$ at 3000RPM. This engine was modified for CNG fuelling. The compression ratio was increased to 13.5 while turbocharging was implemented in order to reach the original engine performances, [1]. The engine was operated strictly stoichiometric and used one pre- and one main TW Catalyst, [19] As reported in [1] and [20] pure CNG operation reduced the $\mathrm{CO}_{2}$ emission by $30 \%$ in respect to the a naturally aspirated gasoline engine of the same performance, while the vehicle reached the Euro-4 and SULEV emission standards, [20]. One cylinder was equipped with a pressure transducer. Cylinder pressure data have been processed by a transient recorder and analyzed by WEG, a heat release software package developed at ETH Zurich, [21]. Engine-out exhaust gas was analyzed by a Horiba MEXA-9200DF analyzer. A separate line of this analyzer was used for measuring $\mathrm{CO}_{2}$ in the intake in order to quantify the amount of EGR. For the operating points of interest in this paper the internal EGR was estimated between 1.8 and 2.3 mass- $\%$, [16].

\section{FUELS}

\begin{tabular}{|c|c|c|c|c|c|}
\hline & & $\mathrm{CH}_{4}$ & $\begin{array}{c}5 \mathrm{vol}-\% \\
\mathrm{H}_{2}\end{array}$ & $\begin{array}{c}10 \mathrm{vol} / \% \\
\mathrm{H}_{2}\end{array}$ & $\begin{array}{c}15 \mathrm{vol} / \% \\
\mathrm{H}_{2}\end{array}$ \\
\hline $\begin{array}{c}\text { Vol.-Frac. } \mathrm{H}_{2} \\
\text { [vol\%] }\end{array}$ & 0 & 5 & 10 & 15 \\
\hline $\begin{array}{c}\text { Vol.-Frac. } \\
\mathrm{CH}_{4}\end{array}$ & {$[\mathrm{vol} \%]$} & 100 & 95 & 90 & 85 \\
\hline $\begin{array}{c}\text { Mass-Frac. } \\
\mathrm{H}_{2}\end{array}$ & {$[$ [mass\%] } & 0 & 0.705 & 1.377 & 2.169 \\
\hline $\begin{array}{c}\text { Mass-Frac. } \\
\mathrm{CH}_{4}\end{array}$ & {$[$ mass\%] } & 100 & 99.29 & 98.623 & 97.831 \\
\hline $\begin{array}{c}\text { Energy-subst. } \\
\mathrm{H}_{2}\end{array}$ & {$[\%]$} & 0 & 1.652 & 3.242 & 5.053 \\
\hline $\begin{array}{c}\text { Stoichiom. Air } \\
\text { Ratio }\end{array}$ & 17.19 & 17.23 & 17.26 & 17.284 \\
\hline $\begin{array}{c}\text { Low Heating } \\
\text { Value }\end{array}$ & $\mathrm{MJ} / \mathrm{kg}$ & 50.02 & 50.492 & 50.964 & 51.519 \\
\hline
\end{tabular}

Table 1: Main properties of the fuels investigated

The compressed natural gas (CNG) used, consisted of 99.5vol-\% Methane, while Hydrogen for the mixtures was of $99.995 \mathrm{vol}-\%$ purity. The mixing has been performed by the supplier prior to filling the fuels into 200 bar bottles. Table 1 summarises the most important fuel properties. It should be mentioned that because of the different energy content of the mixtures (Table 1) we do not consider a direct comparison of b.s.f.c. engine data as appropriate. Therefore instead of fuel consumption statements we strictly report fuel conversion efficiency data. For a more detailed description of the engine and the fuel-blends used the interested reader is referred to [18].

\section{EXPERIMENTAL PROCEDURE}

The results presented in the section "Hydrogen-CNG blends without EGR" have been obtained by measurements on the engine dynamometer. Apart from appropriate corrections for the uncertainties of the exact setting of the engine load the procedure is straight forward. The brake accuracy is in the $0.1 \%$ domain, i.e. at $20 \mathrm{~kW}$ the power uncertainty is less than $0.02 \mathrm{~kW}$. Being limited by the ECU digitization on the fine tuning of the throttle valve position, the setting of the engine load becomes discrete. So although the engine load can be estimated with the above mentioned high accuracy, only discrete values around the required load can be set. Given the fact that with decreasing load, fuel consumption dependency from load sharply increases, we performed all measurements at each spark timing twice. Once at a load slightly under the required one (example: at 1.97 bar bmep in the case with a required bmep of 2.0 bar) and a second time slightly over the required load (example: at 2.02 bar bmep in the case with a required bmep of $2.0 \mathrm{bar})$.

Principles of Design of Experiments (DoE) have been applied for obtaining the results with EGR. Several reasons led to this decision. The most important was given by the ability of DoE procedures to explore a wide parameter space in great detail. DoE methods have been widely discussed in the recent past, [22], [23] and [24]. Specific DoE applications in engine development and optimisation are still an interesting topic [16], [25] and [26]. We will omit here any introduction to DoE. Instead we will briefly describe the procedures chosen and the solutions that had to be developed. The software used in all DoE related steps was Mathworks $®$ Model Based Calibration Toolbox. The interested reader is referred to [18] for detailed information concerning the procedure chosen.

The first step in applying DoE methods consists of dividing the experimental variables into control factors (parameters that can be individually controlled and measured), response factors (parameters, whose variations can be measured directly due to changes in the control factors) and noise factors (which can be measured but not controlled and influence the response factors). The obvious control factors in the present work are the spark timing as well the amount of EGR. Fuel conversion efficiency $\eta_{\mathrm{f}}, \mathrm{NO}_{\mathrm{x}}, \mathrm{CO}, \mathrm{THC}$, exhaust temperature and $\mathrm{CO}_{2}$ comprise the response parameters.

Since our investigations focussed at the lower load regime we had to take into account the sensitive dependence of the engine efficiency on very small load varia- 
tions as described above. In this sense the engine load was an additional control (=noise) parameter.

Afterwards the model for the response parameters has to be defined. For better accuracy we decided to use polynoms of the 3rd degree, [16]. Eq. (1) gives an example of the polynomial used for the fuel conversion efficiency.

$$
\begin{aligned}
& \eta_{f}=\beta_{1}+\beta_{2} S T+\beta_{3} E G R+\beta_{4} b m e p+\beta_{5} S T^{2}+ \\
& \beta_{6} S T \cdot E G R+\beta_{7} S T \cdot b m e p+\beta_{8} E G R^{2}+\beta_{9} E G R \cdot b m e p \\
& +\beta_{10} S T^{3}+\beta_{11} S T^{2} \cdot E G R+\beta_{12} S T^{2} \cdot b m e p+ \\
& \beta_{13} S T \cdot E G R^{2}
\end{aligned}
$$

The next step is the definition of a measurement matrix with several levels of all control parameters. Then the measurements according to the matrix have to be performed on the engine test bench. Thereafter the measurement data is used to build one polynomial model for each response factor by estimating the associated $\beta_{i}$ coefficients through least square fitting. The models have been used for following the behaviour of the response factors in the wide engine operating parameter space investigated. In the vicinity of the emerged optimal settings verification measurements have been performed.

\section{THERMODYNAMIC ANALYSIS}

Engine energy balance yields the distribution of the fuel energy to the various energy outputs of the engine and is a wide applied tool mainly used for the layout of components. Availability (exergy) analysis is more complex and leads to the identification of irreversibilities, [27]. Loss analysis in contrary, aims in identifying, at least theoretically, avoidable losses of the real engine process in respect to an ideal process, which has already taken into account the restrictions of thermodynamics $2^{\text {nd }}$ law. Applications of loss analysis yield to accountable results only if a reliable cylinder pressure monitoring and analysis is in place. Some recent applications are known, [28], [29]. However, we are not aware of any loss analysis reported for engines fuelled by hydrogen-natural gas mixtures except our first results published in [18].

The basis of the loss analysis is the ideal process which for premixed engine combustion systems is described by the constant volume process. The fuel conversion efficiency of the constant volume process, $\eta_{\mathrm{cv}}$, is only a function of the compression ratio $C R$ and $\gamma$, the ratio of the specific heats (under constant pressure and volume) of the working fluid, Eq. (2).

$$
\eta_{c v}=1-C R^{1-\gamma}
$$

Multiplying the energy introduced by the fuel $Q_{b}=m_{f} Q_{L H V}$ with $\eta_{\mathrm{cv}}$ we obtain the remaining energy, which theoretically could be transformed to work at the piston, i.e. theoretically could be fully transformed to the indicated work, $\mathrm{P}_{\mathrm{mi}}$. In real engines though, some additional losses occur, reducing $P_{\mathrm{mi}}$. A brief description of these losses follows. For a more detailed description the interested reader is referred to [17], [18], [28] and [29].

Incomplete combustion losses, $\mathbf{Q}_{\mathrm{ic}}$ : The existence of unburned hydrocarbons, $\mathrm{CO}$ and $\mathrm{H}_{2}$ in the exhaust gives evidence of heat which could have been used in the case of complete combustion. We used the measured concentrations of $\mathrm{CO}$ and $\mathrm{THC}$ in the exhaust, assuming that the THCs were mainly methane and the associated lower heating values.

Real combustion losses, $\mathbf{Q}_{\mathrm{rc}}$ : The constant volume process assumes instant combustion during the piston is at TDC. In reality combustion needs some time. The estimation of the associated losses is more complex. The interested reader is referred to [18].

Cylinder Wall Heat Losses, $\mathbf{Q}_{w h}$ : The computation of the wall heat losses was also performed by WEG (based on the in-cylinder pressure and heat release analysis), [15], using a Woschni, [2] correlation for the heat transfer coefficient $\alpha_{w}$ :

$$
\alpha_{w} \approx s_{p}^{0.8} \cdot p_{c y l}^{0.8} \cdot B^{-0.2} \cdot T_{c y l}^{-0.53}
$$

Pumping Work Losses, $\mathbf{W}_{\mathbf{g x}}$ : The computation of the mean indicated pressure during gas exchange can be achieved by integrating the pressure signal between the opening of the exhaust valve and the closing of the inlet valve:

$$
p_{m i, g x}=\frac{1}{V_{d}} \cdot \int_{E V O}^{I V C} p_{c y l} \cdot d V
$$

Subtracting all the above described losses from the energy introduced by the fuel $Q_{b}$ results in an amount slightly higher than the indicated work:

$$
\begin{aligned}
& Q_{b}-\left(\left(1-\eta_{c v} \cdot Q_{b}\right)+Q_{i c}+Q_{r c}+Q_{w h}+W_{g x}\right)>p_{m i} \cdot V_{d}= \\
& =\oint p_{c y l} \cdot d V
\end{aligned}
$$

In our considerations so far we omitted some "real gas losses", since we assumed for equation (2) that the working fluid is comprised only of air. Also no blow-by losses have been taken into account. We considered the inequality in (5) to be due to these losses. So we use the difference in equation (6) for estimating the resultant "real gas and blow-by" losses, $Q_{\text {rg-bb }}$ :

$$
\begin{aligned}
& Q_{r g-b b}=Q_{b}-\left(\left(1-\eta_{c v} \cdot Q_{b}\right)+Q_{i c}+Q_{r c}+Q_{w h}+W_{g x}\right) \\
& -p_{m i} \cdot V_{d}
\end{aligned}
$$

The difference between the indicated and the effective (break) work was attributed to mechanical friction among the engine parts as well as energy used by auxiliary units of the engine (water, oil pump etc.). 


\section{RESULTS AND DISCUSSION}

The first part of this section aims in improving the understanding of the effects of the different fuel mixtures on the combustion and emission behavior of the engine without external EGR. Therefore all investigations have been performed experimentally on the engine dynamometer. In a second step external EGR was added with the goal of direct comparisons as well as improved analysis of the results. In this second part we apply a combination of experimental results and statistical modeling as described in the former sections.

\section{HYDROGEN-CNG BLENDS WITHOUT EGR}

All results under discussion in this subsection have been obtained with maximal efficiency (MBT) spark timings. The determination of the latter has been performed as described in the Experimental Procedure section.

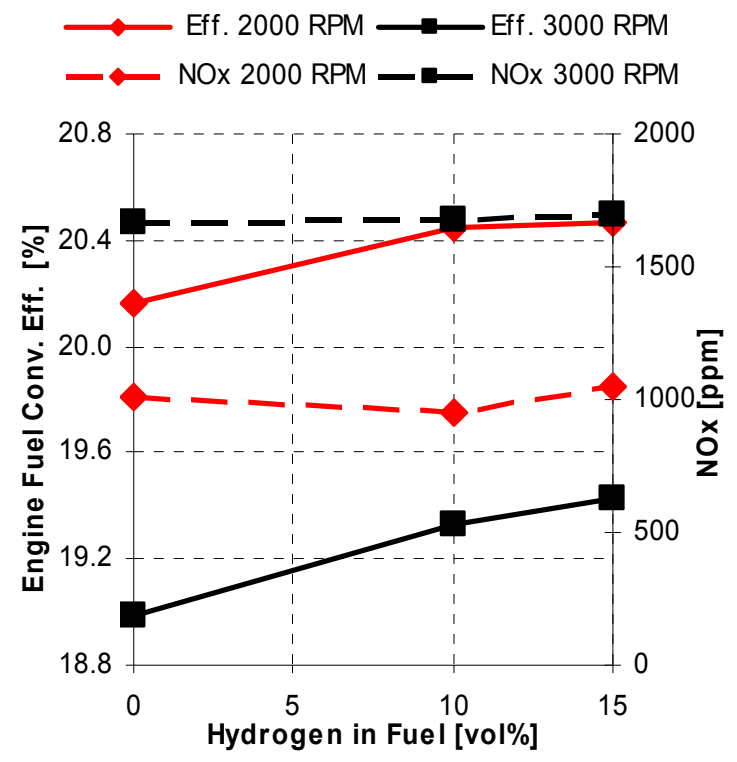

Fig. 1: Engine fuel conversion efficiency and (engineout) $\mathrm{NO}_{x}$ emission at 2 bar bmep and MBT spark timing

Figs. 1 and 2 present the maximal fuel conversion efficiencies (=brake thermal efficiency) and the associated $\mathrm{NO}_{\mathrm{x}}$ emissions reached with each fuel mixture for two engine loads ( 2 and 4 bar respectively). Higher $\mathrm{H}_{2}$ contents of the fuel improve efficiency in the lower engine load, Fig. 1. However, the gains when the $\mathrm{H}_{2}$ content in the fuel surpasses the $10 \mathrm{vol} \%$ are small. The resulting efficiency increase lies at about $1.6 \%$ for both engine speeds in respect to the efficiencies reached with the pure CNG fuel. Noteworthy though are the differences between the low and the higher load, 4 bar in Fig. 2.

Efficiency gains of approx. $2 \%$ can be achieved by increasing the $\mathrm{H}_{2}$ content of the fuel up to $10 \mathrm{vol} \%$. Additional increase of the $\mathrm{H}_{2}$ content of the fuel results in effi- ciency losses. Some explanation therefore is provided by the following loss analysis. As expected the maximal obtainable efficiencies for each load decrease with increasing engine speed. Likewise, the maximal efficiencies for the same RPM increase with increasing engine load.



Fig. 2: Engine fuel conversion efficiency and (engineout) $\mathrm{NO}_{\mathrm{x}}$ emission at 4 bar bmep and MBT spark timing

Engine-out $\mathrm{NO}_{x}$ show also different behavior at the two loads, as presented in Figs 1 and 2. While in the low load (Fig. 1) only modest increase could be identified (marginal increase only for the mixture with the highest $\mathrm{H}_{2}$ content), in the higher load (Fig. 2) engine-out $\mathrm{NO}_{x}$ increase steadily with the $\mathrm{H}_{2}$ richer fuels. Not surprising, $\mathrm{NO}_{x}$ emissions at the low load are significantly lower than those of the higher load. In parallel $\mathrm{NO}_{x}$ emissions at the low RPM are significantly lower than those at the higher RPM.

In Figs 3 and 4 we display the engine-out total unburned hydrocarbons (THC) and $\mathrm{CO}$ at the examined engine speeds and loads. The $\mathrm{CO}$ tendencies are clear: Increasing $\mathrm{H}_{2}$ content in the fuel decreases $\mathrm{CO}$. However, the decrease is only moderate especially in the higher engine load (4bar bmep, Fig. 4), where the differences among the different fuel compositions are marginal. The THC behavior on the other hand is more interesting. While the THC emission decreases sharply with the 10vol\% $\mathrm{H}_{2}$-CNG fuel blend, further increase of the $\mathrm{H}_{2}$ content increases engine-out THC. The higher combustion rate with increasing $\mathrm{H}_{2}$ portion in the fuel mixture is initially leading to lower THC engine-out emissions. The THC increase with additional $\mathrm{H}_{2}$ in the fuel is rather surprising. Moreover this increase is evident in both speeds and both loads investigated, as well as when using $E G R$, as reported in [18]. One possible explanation could be that the decreasing flame quenching distance (pure hydrogen has approx. 1/3 of the flame quenching distance of CNG, [7]) allows the flame to approach 
closer to the cylinder wall. This reduces the THC due to unburned fuel, increases cylinder wall temperature and THC from the lube oil.

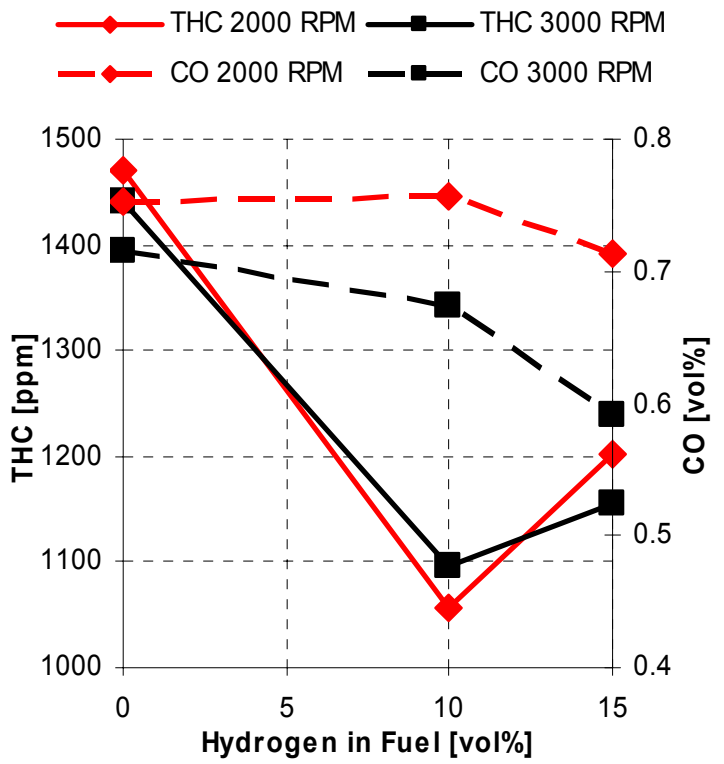

Fig. 3: Total unburned hydrocarbon and $\mathrm{CO}$ (engine-out) emissions, at 2bar bmep and MBT spark timing

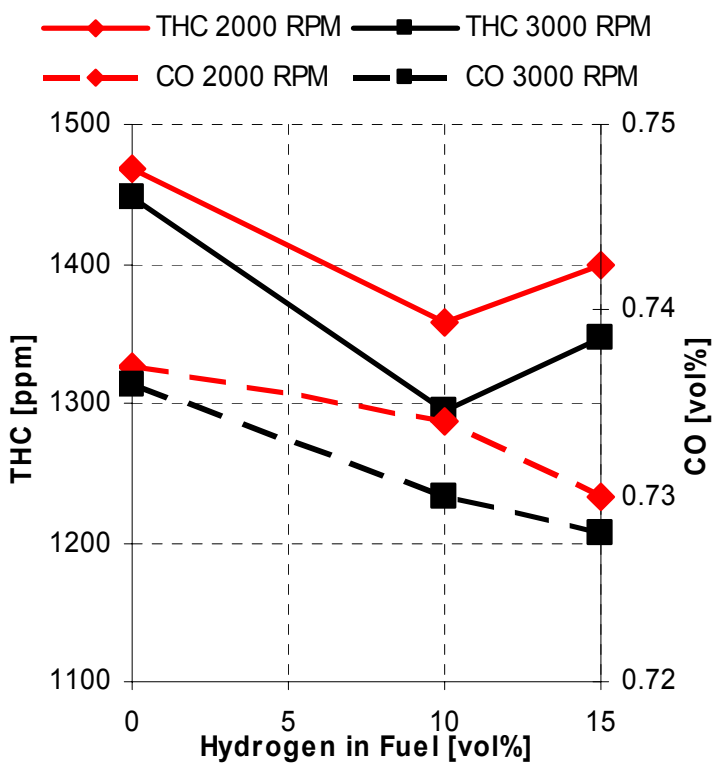

Fig. 4: Total unburned hydrocarbon and $\mathrm{CO}$ (engine-out) emissions, at 4 bar bmep and MBT spark timing

Heat release analysis based on the in-cylinder pressure trace was used for obtaining the averaged in-cylinder temperature. In Fig. 5 we present the results for the examined fuels at 2000RPM and 4 bar bmep. This operating point was chosen as a typical one for the higher loads examined, while our preliminary analysis in [18] provided first results for the 2000RPM and 2bar bmep.
Comparing the pressure traces in Fig. 5 it is obvious that the $\mathrm{H}_{2}$ enriched fuels reach higher pressures during end compression than the pure CNG fuel. There is though practically no pressure trace difference between the two $\mathrm{H}_{2}$ enriched fuels. Peak pressure reached with the $15 \mathrm{vol} \% \mathrm{H}_{2}$-CNG fuel amounts 36.1 bar in comparison to $35.9 \mathrm{bar}$ and $34.9 \mathrm{bar}$ reached with the $10 \mathrm{vol} \% \mathrm{H}_{2}$-CNG and the pure CNG respectively. Noteworthy is that the peak pressure is reached at almost 373 crankangle degrees with all three fuels. Anyway the pressure traces are in accordance with the lower achieved efficiency of the 15 vol\% fuel reported in Fig. 2, since the higher energy of the fuel could obviously not be converted to additional mechanical work. In contrary the temperature traces show significant differences. With the $\mathrm{H}_{2}$ richest fuel not only higher peak temperatures but also higher temperatures throughout the entire expansion stroke prevail. This is additional evidence for the lower efficiency potential with the $\mathrm{H}_{2}$ richest fuel. It is also evidence for the highest engine-out $\mathrm{NO}_{x}$ as reported in Fig. 2.

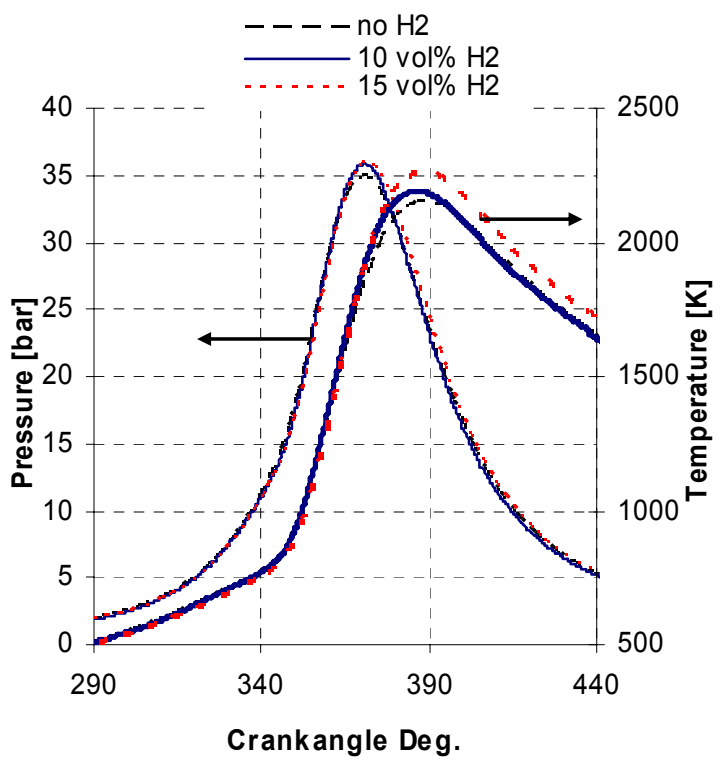

Fig. 5: Average pressure and temperature time histories, 2000RPM and 4bar bmep

The most interesting behavior is exhibited by the $10 \mathrm{vol} \%$ $\mathrm{H}_{2}$ fuel. While peak cylinder temperatures are higher than those obtained with the pure CNG, temperatures during expansion are the lowest.

Deeper insights in the combustion properties of the examined fuels can be achieved when comparing the time scales (most suitably expressed in crankangle degrees) required for burning a certain percentage of the cylinder mass. In Figs 6 and 7 we show the optimal spark timings as well as the elapsed period thereafter for burning $5 \%$ (MFB5), 50\% (MFB50) and 90\% (MFB90) of the cylinder gases. Figure 6 demonstrates the impact of the fuels at 2000RPM on the optimal spark timing as well as on MFB5, MFB50 and MFB90. 


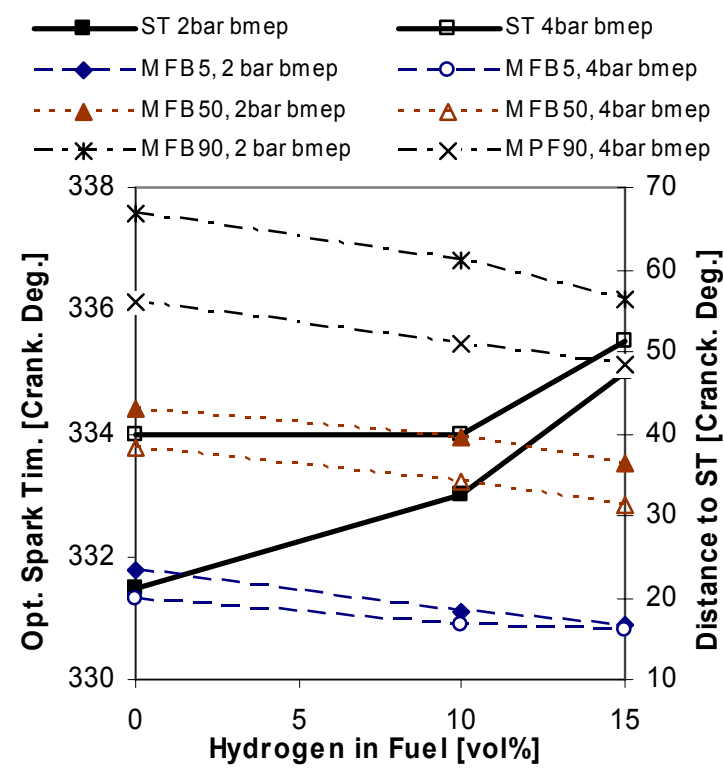

Fig. 6: Optimal Spark Timing (ST) and duration for 5\%, $50 \%$ and $90 \%$ mass fraction burned (MFB5, MFB50 and MFB90 respectively) at 2000RPM

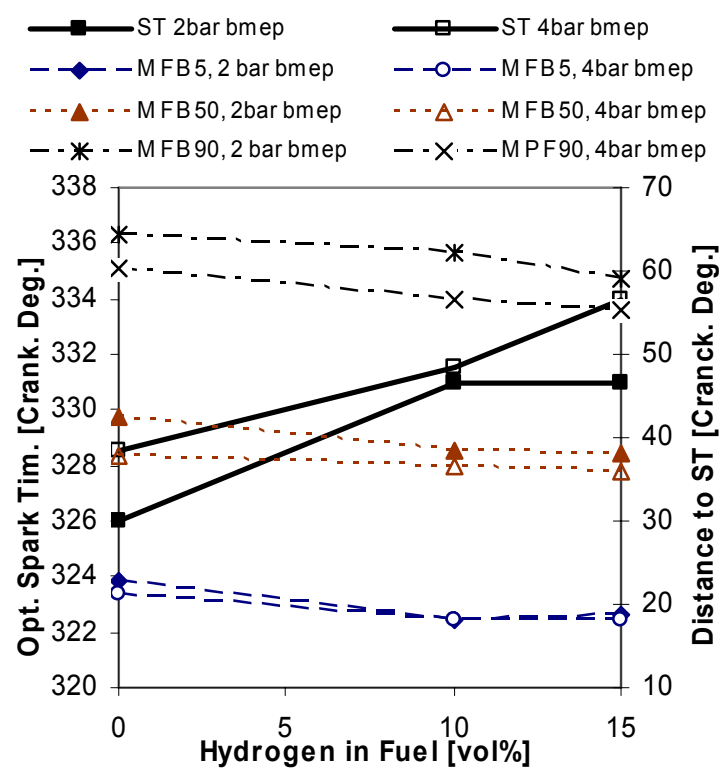

Fig. 7: Optimal Spark Timing (ST) and duration for 5\%, $50 \%$ and $90 \%$ mass fraction burned (MFB5, MFB50 and MFB90 respectively) at 3000RPM

Spark timing depends, of course, on flame speed. So the optimal spark timings for the low load are significantly advanced in respect to the higher load. In addition it is characteristic that the $\mathrm{H}_{2}$ rich fuels accelerate the combustion process and need less spark timing advance than the pure CNG fuel to achieve CNG. The highest differences of optimal spark advances in respect to the pure CNG are associated with the hydrogen richest fuel, reaching 5 crankangle degrees. This is in good agreement with the findings of other studies; in particular the summary in [7] where hydrogen addition up to $60 \mathrm{vol} \%$ decreases spark timing by $6-14$ crankangle degrees at identical equivalence ratios (although one should keep in mind that the engine in [7] was larger and the investigations were carried out in substantially lower engine speeds).

The initial combustion phase (MFB5) is shortened by more than $20 \%$ with the $10 \mathrm{vol} \% \mathrm{H}_{2}$-CNG fuel blend at the lower load, and by more than $15 \%$ at the higher load. Interestingly further increase of the $\mathrm{H}_{2}$ content of the fuel accelerates the initial combustion phase by only approx. $7 \%$ at the low load (2bar bmep), and $5 \%$ at the higher load (4bar bmep). In contrary to the initial combustion phase (MFB5), the combustion acceleration in the following two phases is rather modest, these observations being in good agreement with findings of [2], [3], [4] and [5] were hydrogen-gasoline mixtures have been examined. The $10 \mathrm{vol} \% \mathrm{H}_{2}-\mathrm{CNG}$ fuel blend shortens the main combustion part (MFB50) by around $9 \%$ while the additional impact of the $\mathrm{H}_{2}$ richest fuel is somehow less $(7 \%)$. The MFB50 shortening is similar for both loads. The shortening of the overall combustion as expressed by the MFB90 crankangle interval is similar to the shortening the MFB50 part.

No essentially different observations can be made at the higher examined engine speed, 3000RPM (Fig. 7). The initial combustion phase is similarly accelerated as at the lower engine speed by the $10 \mathrm{vol} \% \mathrm{H}_{2}$-CNG fuel blend. The impact of the $15 \mathrm{vol} \% \mathrm{H}_{2}$-CNG fuel blend is even weaker at $3000 \mathrm{RPM}$. There was practically no significant additional acceleration of the initial combustion phase in combination with the $\mathrm{H}_{2}$ richest fuel mixture. In addition the acceleration of the two later stages of the combustion through the $\mathrm{H}_{2}$ containing fuel blends was weaker when compared to the acceleration reported for the 2000RPM.

Noteworthy is that according to Figs 6 and 7 the optimal efficiency spark timings have led to such combustion placements that MFB50 was reached at around 368-369 deg. CA regardless of the fuel, the engine speed or the load. Only at 2000RPM and the low load the optimal spark timing led to a combustion positioning such, that the MFB50 was reached at $372 \mathrm{deg}$. CA, this again being not depended on the fuel composition.

In parallel with combustion analysis, loss analysis is a powerful tool for explaining the phenomena. Figs. 8 and 9 show the loss analysis results at 2000 and 3000rpm respectively each plot at $4 \mathrm{bar}$ bmep engine load. The efficiency of the constant volume process depends only on the compression ratio and the thermodynamic properties of air. 


\begin{abstract}
$\square$ Fuel Conv. Eff. $\quad \boxminus$ Mecanical
$\square$ Real Gas, Blow -by $\square$ Gas exchange

$\square$ Heat Transfer $\quad \square$ Real Comb.

$\square$ Incomplete Comb. $\square$ Const. Vol. Eff.
\end{abstract}

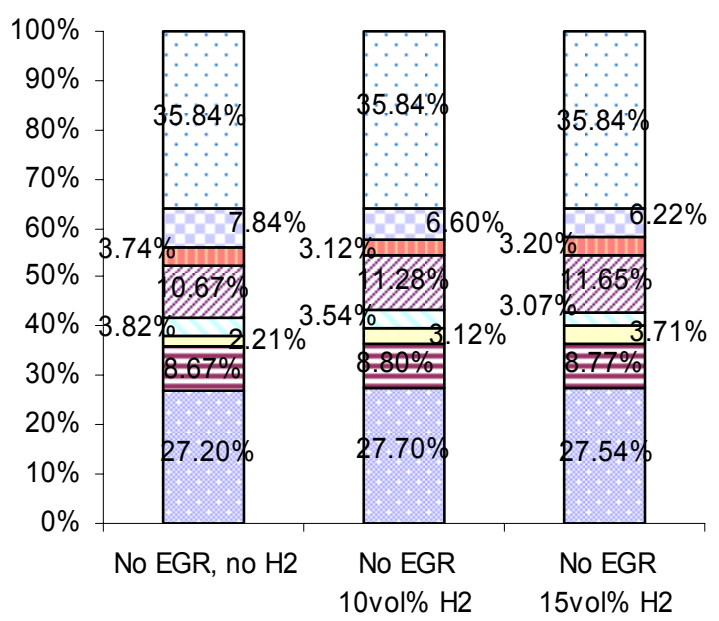

Fig. 8: Loss analysis at 2000RPM and 4bar engine load with efficiency optimal spark timing

$\begin{array}{ll}\square \text { Fuel Conv. Eff. } & \square \text { Mecanical } \\ \square \text { Real Gas, Blow -by } & \square \text { Gas exchange } \\ \square \text { Heat Transfer } & \square \text { Real Comb. } \\ \square \text { Incomplete Comb. } \quad \square \text { Const. Vol. Eff. }\end{array}$

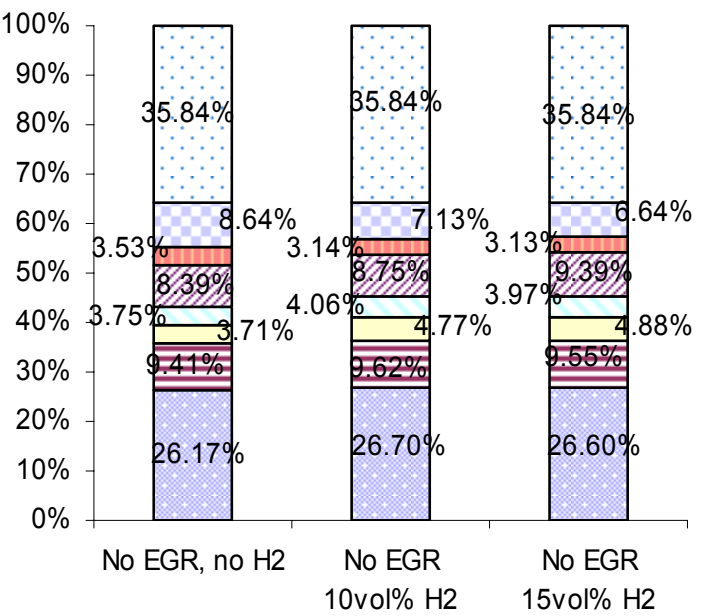

Fig. 9: Loss analysis at 3000RPM and 4bar engine load with efficiency optimal spark timing

As already discussed in the thermodynamic analysis section we assumed the cylinder charge to be comprised only of air. We considered the associated error as a "loss", together with the also not further quantified blow- by losses, and included them in $\mathrm{Q}_{\mathrm{rg}-\mathrm{bb}}$, as described by equation (6). For the three examined fuels the efficiency of the constant volume process is consequentially the same and amounts $64.16 \%$. In this sense the non avoideable losses due to the second law of thermo- dynamics amount to $35.84 \%$ Incomplete combustion losses decrease with increasing hydrogen portion in the fuel. The tendency is the same for both examined engine speeds (Fig. 8 and 9).

While with pure CNG incomplete combustion losses amount to $7.84 \%$ of the energy introduced by the fuel (2000RPM, Fig. 8) they are reduced to $6.60 \%$ with the $10 \mathrm{vol}-\% \mathrm{H}_{2}$-CNG fuel blend and to $6.22 \%$ with the $15 \mathrm{vol}-$ $\% \mathrm{H}_{2}$-CNG fuel blend. Obviously the decrease flattens being a consequence of the uprising THC emissions with the hydrogen richest fuel (Fig 4).

Loss analysis confirms that the hydrogen enrichment accelerates combustion. The real combustion losses decrease from $3.74 \%$ when using pure CNG to $3.12 \%$ with the fuel containing $10 \mathrm{vol}-\% \mathrm{H}_{2}$. Interestingly though no further decrease of the real combustion losses is evident when using the $15 \mathrm{vol}-\% \mathrm{H}_{2}$-CNG fuel blend. This is an indication that no significant combustion_acceleration takes place with the additional increase of the hydrogen portion in the fuel. The wall heat losses on the other hand increase with increasing $\mathrm{H}_{2}$ content of the fuel. As expected, a comparison of the relative portion of the wall heat losses between the two engine speeds shows higher values at the 2000RPM (from $10.67 \%$ to $11.65 \%$ vs. from $9.41 \%$ to $9.62 \%$ at $3000 \mathrm{RPM}$ ), reflecting the lower available time for heat transfer at the higher engine speeds. No clear tendency can be seen concerning the gas exchange losses. Although hydrogen's stoichiometric air-to-fuel ratio is higher, hydrogen occupies a greater portion of volume with respect to air, than does methane. This, in effect, counters hydrogen's lower volumetric heat $Q_{\mathrm{LHV}}$ so that stoichiometric mixtures of hydrogen and air contain slightly less energy (2913 $\mathrm{kJ} / \mathrm{m}^{3}$ ) than stoichiometric methane air $\left(3088 \mathrm{~kJ} / \mathrm{m}^{3}\right)$. In effect this should lead in less required throttling of the engine for reaching a certain power and this should be reflected in the decreasing gas exchange losses with increasing hydrogen content of the fuel. Probably the effect is too small to be detected in our case.

The loss analysis results for the low load point (2000RPM and 2bar bmep), [18], are in good agreement with those in Fig. 8. The real combustion losses are substantially higher at the lower load. Also wall heat transfer losses attributed to the lower temperatures prevailing at the lower load. On the other hand gas exchange losses are substantially higher at the lower load, while the portion of the mechanical losses increases.

\section{HYDROGEN-CNG BLENDS WITH EGR}

EGR in modern SI-engines is mainly used for reducing engine-out $\mathrm{NO}_{x}$ emissions. In addition there is possible improvement in fuel consumption due to three factors: (1) reduced pumping work, since for the same brake load less throttling is required (higher amount of inert gas as well as higher temperature of the intake gas), (2) reduced heat loss to the walls because of reduced burn 
gas temperature and (3) a reduction in the degree of dissociation in the high temperature burned gases.

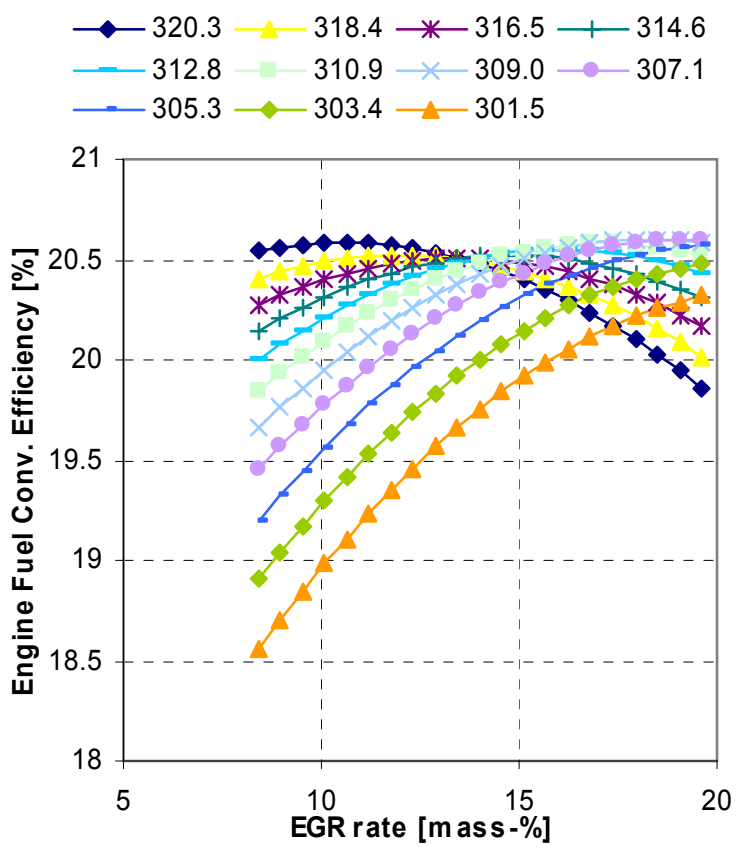

Fig. 10: Break fuel conversion efficiency vs. EGR for different spark timings as predicted by the DoE modeling at 2000RPM and 2bar bmep using the $10 \mathrm{vol} \% \mathrm{H}_{2}$-CNG fuel blend

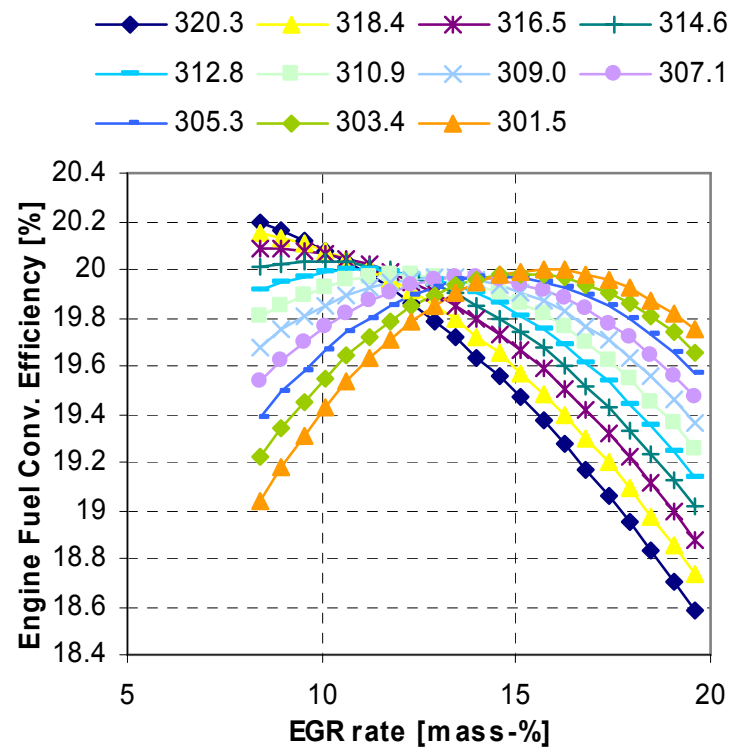

Fig. 11: Break fuel conversion efficiency vs. EGR for different spark timings as predicted by the DoE modeling at 2000RPM and 2bar bmep using pure CNG fuel

The use of EGR to lower $\mathrm{NO}_{\mathrm{x}}$ emissions has a direct effect on the stability of the combustion process, since the presence of inert gas in the combustion chamber hinders the ignition of the mixture, the formation growth of the burning kernel and the subsequent propagation of the flame front through the combustion chamber. In this section we will present an in-depth analysis of the results at 2000RPM and 2bar bmep engine load operating the engine with different fuel blends. In order to gain more understanding we introduced also an additional fuel comprised of $5 \mathrm{vol} \% \mathrm{H}_{2}$.

Fig. 10 displays the predicted break fuel conversion efficiency of the engine for a series of spark timings vs. EGR rate for the $10 \mathrm{vol} \% \mathrm{H}_{2}$-CNG fuel blend. An advantage of DoE modelling is obvious: The possibility of detailed exploration of the parameter space (the resolution in Fig. 10 is arbitrary and can be chosen upon user demand, in addition different views of the parameter space are also possible, as an example to mention an efficiencies over spark timings diagram for different EGR rates).

In any case Fig. 10 contains some important information: Efficiencies exceeding $20.6 \%$ are achievable. In comparison to Fig. 1 additional $1 \%$ increase in efficiency is possible, attributable to the EGR. In addition predicted are two possibilities achieving maximal efficiency: Either with low EGR and late spark timing (10mass\% EGR and ST at 320 crankangle deg.) or with high EGR and earlier spark timing (approx. 16mass\% EGR and ST at 308 crankangle deg.). Interestingly the second possibility is not available without hydrogen, Fig. 11. There are some early spark timings leading to an efficiency peak at the high EGR domain, this peak though is significantly lower than the maximum efficiency at late spark timing with low EGR.

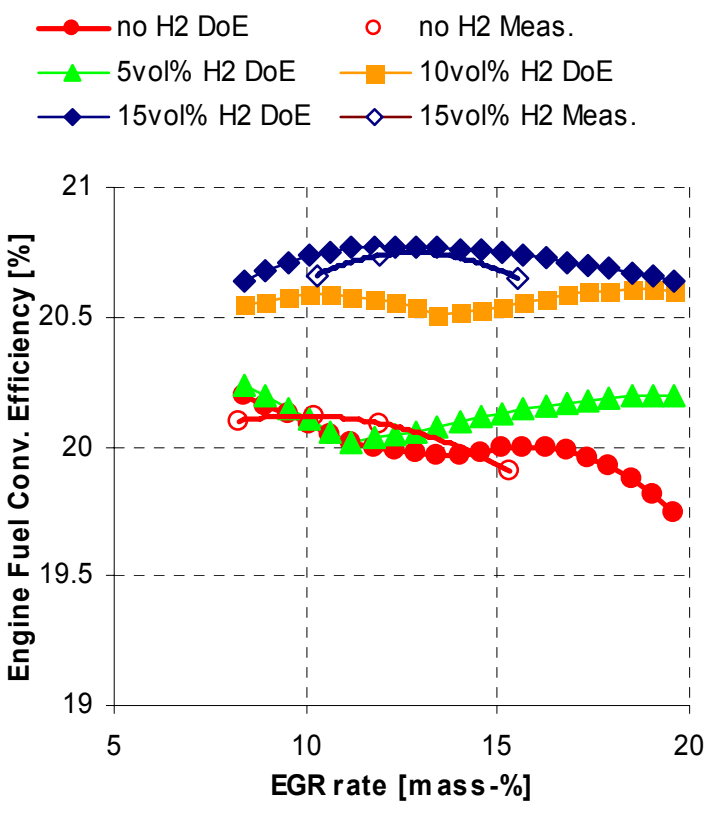

Fig. 12: Break fuel conversion efficiency vs. EGR quantity using efficiency optimal spark timing (2000RPM, 2bar bmep)

Nevertheless the enveloping curve can provide the maximal efficiencies achievable by each EGR rate for the examined fuel combinations choosing for each EGR 
rate the efficiency optimal spark timing. We plot the results in Fig. 12 together with some verification measurements performed on the engine dynamometer using the predicted combinations of the control parameters.

The highest fuel conversion efficiency of $20.8 \%$ is obtained with the $\mathrm{H}_{2}$ richest fuel and around $12.5 \mathrm{mass} \%$ EGR. In comparison the highest fuel conversion efficiency with no EGR and no $\mathrm{H}_{2}$ is $20.15 \%$ while the highest efficiency with $15 \mathrm{vol} \% \mathrm{H}_{2}$ and no EGR was $20.4 \%$ (see Fig. 1). The increase of maximal efficiency without EGR caused by the $\mathrm{H}_{2}$ richest fuel is $2 \%$, while adding optimal EGR increases the maximal efficiency for additional $1.5 \%$. Similar efficiency increases have been found in [6] and [7] for stoichiometric combustion $(\lambda=1)$ with and without EGR although the engines were not directly comparable. Even similar efficiency gains have been reported when partly substituting gasoline with $\mathrm{H}_{2}$, while using EGR, [2].



Fig. 13: Engine-out NOx emissions vs. EGR quantity using efficiency optimal spark timing (2000RPM, 2bar bmep).

Apart from the satisfying agreement among measurements and verifications, some additional features of Fig. 12 are of interest. Using the $5 \mathrm{vol} \% \mathrm{H}_{2}$-CNG fuel blend seems not to affect the combustion, at least with low EGR and early spark timing combinations. There are hardly any differences to the pure CNG fuel. Differences appear though, in the high EGR domain. Even the small fraction of hydrogen in the fuel influences the combustion with heavy EGR leading to significant improvements in efficiency. Nevertheless the impact of the $5 \mathrm{vol} \% \mathrm{H}_{2}$ fuel is rather weak. Another important feature is the difference in efficiency improvement among the hydrogen richer fuels. Without EGR there were practically no improvements with the hydrogen richest fuel (Fig.1). With
EGR the improvements are substantial, as can be seen by Fig. 12 .

Fig. 13 shows the DoE predicted engine-out $\mathrm{NO}_{\mathrm{x}}$ emissions vs. EGR rate (using the predicted spark timings for highest efficiency). We also plot the corresponding verification measurements on the engine. While the predictions are lower than the measurements, tendencies are similar. As expected, with increasing $E G R \mathrm{NO}_{x}$ emission decreases. This decrease is not monotonous. After a certain EGR amount, the $\mathrm{NO}_{\mathrm{x}}$ increase again, at least for the pure CNG, the $5 \mathrm{vol} \%$ as well as the $10 \mathrm{vol}-\% \mathrm{H}_{2}-$ CNG fuel blend, while for the $15 \mathrm{vol} \% \mathrm{H}_{2}$ fuel the decrease is continuous. The rather surprising increase at the mid-EGR rates, verified also by the measurements, can be attributed to the changing spark timing. It should be reminded, that each point shown in Fig. 13 has individual spark timing, the one yielding highest fuel conversion efficiency (gradually advanced with increasing EGR rate. Nevertheless the $\mathrm{NO}_{\mathrm{x}}$ emissions are very low compared to those without EGR; the measured $\mathrm{NO}_{\mathrm{x}}$ for each of the examined fuels with no EGR at the maximal efficiency spark timing was over 1000 ppm (Fig. 1). In other words using the $15 \mathrm{vol}-\% \mathrm{H}_{2}-\mathrm{CNG}$ mixture in combination with optimal EGR (12.5 mass-\%, acc. to Fig. 12) leads to over $3 \%$ fuel conversion efficiency increase with approx. $45 \%$ engine-out $\mathrm{NO}_{x}$ reduction. Lower engineout $\mathrm{NO}_{x}$ not only result in lower after-catalyst $\mathrm{NO}_{x}$. The rhodium content of the TW catalyst can be substantially reduced, lead to significant cost reduction given the continually increasing rhodium prices in the last years.

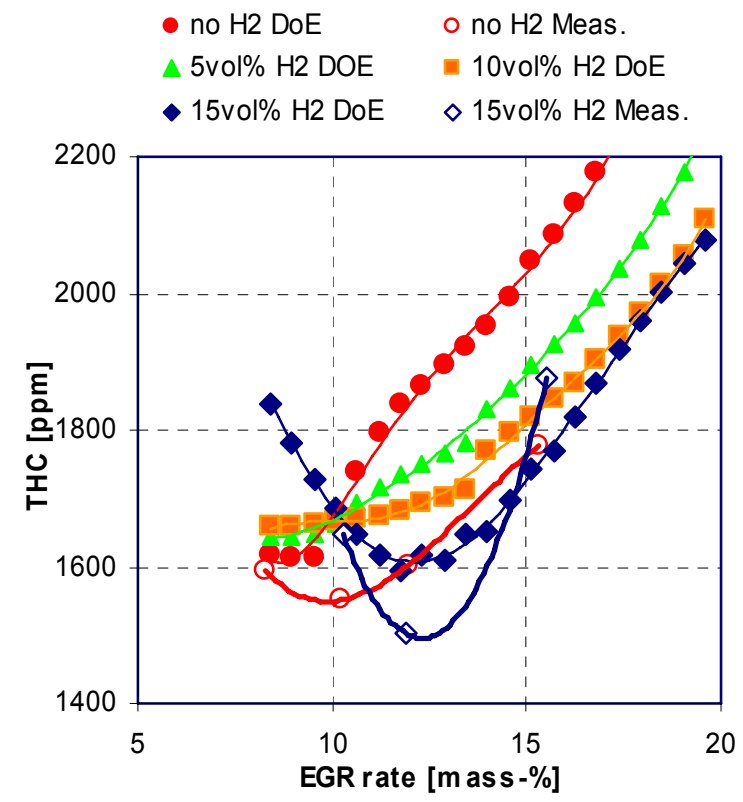

Fig. 14: Engine-out THC emissions vs. EGR quantity using efficiency optimal spark timing (2000RPM, 2bar bmep).

Fig. 14 shows the corresponding Total Unburned Hydrocarbon (THC) engine-out emissions vs. EGR rates using the predicted spark timing for highest efficiency. We also plot the corresponding verification measurements on the 
engine. The verification measurements are lower than the predictions, the tendencies though are similar. In general, increasing EGR results in increased unburned hydrocarbon emissions due to slower combustion and stronger flame quenching tendencies in and around crevices of the combustion chamber. In Fig. 14 we see the minimal THC emission, roughly at $1500 \mathrm{ppm}$ when using the efficiency optimal EGR rate of $12.5 \%$ in combination with the richest $\mathrm{H}_{2}$ fuel. According to Fig. 3 the THC emission with the same fuel and no EGR was around 1350ppm for optimal efficiency,. Using 15vol\% $\mathrm{H}_{2}$ fuel as well as optimal EGR leads to over $3 \%$ fuel conversion efficiency increase while the increase of the engine-out THC emissions lies at $11 \%$. Ambiguous are the tendencies of the engine-out THC with respect to the different fuels. Expected was that the higher combustion rate with increasing $\mathrm{H}_{2}$ portion in the fuel mixture should lead to lower THC engine-out emissions. Neither the measurements without, nor the ones with EGR showed a clear tendency. Accordingly the DoE predictions did not solve this ambiguity. One possible explanation, already discussed, could be that the decreasing flame quenching distance allows the flame to approach closer to the cylinder wall. This reduces the THC due to unburned fuel, increases cylinder wall temperature and THC from the lube oil.

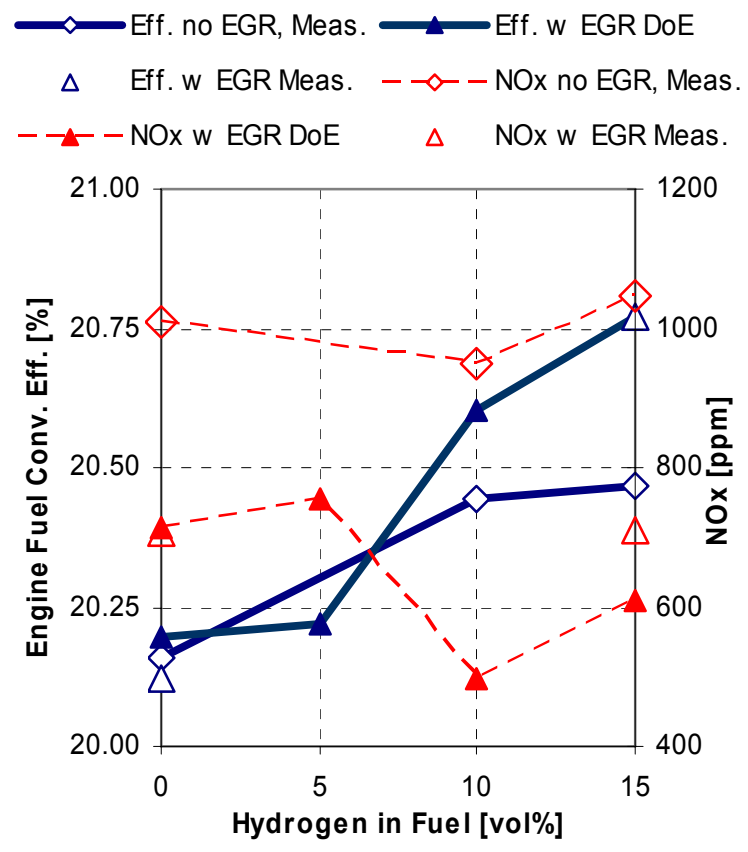

Fig. 15: Engine fuel conversion efficiency and (engineout) NOx emission at 2000RPM and 2bar. Comparison of the predicted and measured effect of EGR

Increasing EGR leads to decreasing engine-out CO emissions. The predicted tendency was also verified by the measurements although the predicted higher $\mathrm{CO}$ emissions of the rich $\mathrm{H}_{2}$ fuel were not confirmed by the verification measurements. Nevertheless $\mathrm{CO}$ emissions were only weakly affected by the type of fuel as well as the EGR amount. Therefore we do not add an associated plot, refer to Figs 3 and 4 or to [18]. Fig. 15 is sum- marizing the most important characteristics when addressing the possible improvements with the appropriate amount of EGR. With pure CNG, EGR should increase only slightly the efficiency of the engine according to the predictions. The verification measurements showed even a slight deterioration. Nevertheless measurements and predictions show that in combination with the "slow" pancake type combustion chamber, if any potential of EGR exists in improving the efficiency, it is very thin. Of course EGR reduces strongly engine-out $\mathrm{NO}_{\mathrm{x}}$. Increasing the $\mathrm{H}_{2}$ part in the fuel though results in substantial advantages, for the efficiency as well as for the $\mathrm{NO}_{\mathrm{x}}$ if the appropriate amount of EGR and the correct spark timing are used.

\section{CONCLUSIONS}

We have demonstrated the potential of $\mathrm{H}_{2}$-CNG blends in increasing the efficiency of a CNG-optimized passenger car production engine.

Operating the engine without any external EGR resulted in:

- Efficiency gains of approx. $2 \%$ by increasing the $\mathrm{H}_{2}$ content of the fuel up to $10 \mathrm{vol} \%$.

- Modest additional efficiency gains at low loads and even losses at higher loads by further increasing the $\mathrm{H}_{2}$ contents of the fuel.

- Increase of engine-out $\mathrm{NO}_{x}$, by almost $3 \%$ at low loads and $8 \%$ at the higher loads examined with increasing $\mathrm{H}_{2}$ contents of the fuel.

- Decrease of engine-out CO by more than $5 \%$ and $\mathrm{THC}(20 \%$ at low and $10 \%$ at the higher loads) with increasing $\mathrm{H}_{2}$ fuel component, although if the $\mathrm{H}_{2}$ content in the fuel surpasses 10 vol\% the gains are partially offset.

The hydrogen component of the fuel accelerates combustion. Therefore less spark timing advance is required for optimal efficiency.

- Losses due to combustion duration decrease, while losses due to cylinder wall heat transfer increase with increasing $\mathrm{H}_{2}$ content in the fuel

Substantial amounts of exhaust gas recirculation (EGR) have a strong impact on the combustion process:

- Two efficiency optimal combustion regimes appear; low EGR and late spark timing as well as high EGR and early spark timing.

- High efficiencies with high EGR and early spark timing (with very low engine-out $\mathrm{NO}_{\mathrm{x}}$ ) can be reached only with the hydrogen rich fuels. 
- With EGR additional 1\%-1.5\% efficiency increase is achievable at part load conditions, mainly due to dethrotteling i.e. reduction of gas exchange work

- The hydrogen richest fuel blend leads to clear efficiency advantages with EGR

\section{ACKNOWLEDGMENTS}

The authors would like to express their gratitude to C. Bach, head of the Laboratory for I.C. Engines at Empa for his support to the project. We would like also to express our thanks to R. Ziegler for his important contribution to all mechanical tasks. We are also grateful to $P$. Rebecchi for his assistance in various DoE, programming and data handling problems.

\section{REFERENCES}

1. Bach C, Lämmle C, Bill R, Soltic $P$, Dyntar D, Janner $P$, Boulouchos $K$, Onder $C$, Landenfeld T, Kercher L, Seel O, Baronick J. Clean Engine Vehicle. A Natural Gas driven Euro-4/SULEV with 30\% CO2-Emissions, SAE Paper 2004-01-0645, 2004

2. Conte E, Boulouchos K. Influence of hydrogenrich gas addition on combustion, pollutant formation and efficiency of an IC-SI engine, SAE Paper 2004-01-0972, published in SAE Transactions 2004, Vol. 113, Sec. 3, Journal of Fuels and Lubricants

3. Allgeier T., Klenk M, Landenfeld T, Conte E, Boulouchos K. Advanced Emission and Fuel Economy Concept using Combined Injection of Gasoline and Hydrogen in SI-Engines, SAE Paper 2004-01-1270, 2004

4. Tully E. J, Heywood J. B: Lean-Burn Characteristics of a Gasoline Engine Enriched with Hydrogen from a Plasmatron Fuel Reformer, SAE Paper 2003-01-0630, 2003

5. Topinka JA, Gerty MD, Heywood JB, Keck JC. Knock Behavior of a Lean-Burn, H2 and CO Enhanced, SI Gasoline Engine Concept, SAE Paper 2004-01-0975, 2004

6. Akansu SO, Dulger Z, Kahraman N, Veziroglu TN. Internal combustion engines fuelled by natural gas hydrogen mixtures, Int. Journal of Hydrogen Energy 29, pp 1527-1539, 2004

7. Bauer CG, Forest TW. Effect of hydrogen addition on the performance of methane-fuelled vehicles. Part I: effect on S.I. engine performance, Int. Journal of Hydrogen Energy 26, pp 55-70, 2001

8. Bade Shrestha SO, Karim GA. Hydrogen as an additive to methane for spark ignition engine applica- tions, Int. Journal of Hydrogen Energy 24, pp 577-586, 1999

9. Larsen JF, Wallace JS. Comparison of Emissions and Efficiency of a Turbocharged lean-burn natural gas and hythane fuelled engine, J. Eng. Gas Turbines Power, 119, 218-26, 1997

10. Sierens R, Rosseel E. Variable Composition hydrogen/natural gas mixtures for increased engine efficiency and decreased emissions, J. Eng. Gas Turbines Power, 122, 135-40, 2000

11. Blarigan PV, Keller JO. A Hydrogen-Fueled Internal Combustion Engine Designed for Single Speed/Power Preparation, Int. J. Hydrogen Energy 2002, 23(7), 603-609.

12. Wong YK, Karim GA. An Analytical Examination of the Effects of Hydrogen Addition on Cyclic Variations in Homogeneously Charged Compression-Ignition Engines, Int. Journal of Hydrogen Energy 25, pp 12171224, 2001

13. Huang Z, Wang J, Liu B, Zeng K, Yu J, Jiang D. Combustion Characteristics of a Direct-Injection Engine Fuelled with Natural Gas-Hydrogen Blends under Various Injection Timings, Energy and Fuels 20, 1498-1504, 2006

14. Allenby S, Chang WC, Megaritis A, Wyszynski $M L$, Hydrogen enrichment: A way to maintain combustion stability in a natural gas fuelled engine with exhaust gas recirculation, the potential of fuel reforming, Proc Intr. Mech Eng Part D 215, 405-18, 2001

15. Heffel JW. $\mathrm{NO}_{\mathrm{x}}$ emission and performance data for a hydrogen fueled internal combustion engine at $1500 \mathrm{rpm}$ using exhaust gas recirculation. Int. Journal of Hydrogen Energy 28, 901-908, 2003

16. Rebecchi P. Untersuchung des Potentials von Abgasrückführung im schnelllaufenden Erdgasmotor mit Verwendung von D.o.E Methoden. Semesterarbeit, Empa, IET-LAV, ETH Zurich, 2005

17. Rechsteiner $\mathrm{C}$. Thermodynamische Beurteilung unter-schiedlicher Verbrennungsabstimmungen in einem Erdgasmotor, Diploma Thesis, Empa, IET-LAV ETH Zurich, 2006

18. Dimopoulos P, Rechsteiner C, Soltic P, Laemmle C, Boulouchos K. Increase of passenger car engine efficiency with low-engine-out emissions using Hydrogen-natural gas mixtures: A thermodynamic analysis. Int. Journal of Hydrogen Energy, doi: 10.1016/j.ijhydene. 2006.12.026, 2007

19. Bach C. Concept of an Exhaust Gas Aftertreatment for Methane-Gas Powered Vehicles, International 
Conference on Low Carbon Fuels, Empa Akademie, November 2005

20. Soltic P. Dedicated Powertrain Technology for methane Powered Cars, International Conference on Low Carbon Fuels, Empa Akademie, November 2005

21. WEG, Rechenprogramm zur Berechnung des Wärmeentwicklungsgesetzes aus gemessenen Brennraumdruckverläufen von Diesel- und Ottomotoren, Benutzerhandbuch und Programmdokumentation, IET-LAV ETH Zurich, September 2005

22. Box G, Hunter W, Hunter JS. Statistics for Experimenters. An introduction to Design, Data Analysis, and Model Building, John Wiley and Sons, 1978

23. Fontan R, Irato G. La Sperimentazione Attraverso l'Applicazione die Strumenti DoE. Un Contributo al Miglioramento dell' Efficienza nell' Impiego della Strumentaione di Laboratorio, Torino TQS-DQX, 1994

24. Barrentine L. An Introduction to design of Experiments. A Simple Approach, ASQ Quality Press, Miwaukee, Wisconsin, 1999

25. Edwards SP, Pilley AD, Michon S, Fournier G. The Optimisation of Common Rail FIE Equipped Engines through the use of Statistical Experimental Design, Mathematical Modelling and Genetic Algorithms, SAE 971635, 1997

26. Dimopoulos $P$, Schöni A, Eggimann A, Sparti C, Vaccarino E, Operti C. Statistical Methods for Solving the Fuel Consumption/Emission Conflict on DI-Diesel Engines. SAE 1999-01-1077, 1999

27. Rakopoulos CD, Kyritsis DC. Hydrogen enrichment effects on the second law analysis of natural and landfill gas combustion in engine cylinders. Int. Journal of Hydrogen Energy, 2005

28. Golloch R. Downsizing bei Verbrennungsmotoren, Springer Verlag, Berlin Heidelberg, 2005

29. Witt A. Analyse der thermodynamischen Verluste eines Ottomotors unter den Randbedingungen variabler Steuerzeiten, $\mathrm{PhD}$ Thesis, Technische Universität Graz, Institut für Verbrennungskraftmaschinen und Thermodynamik, Graz, 1999

\section{CONTACT}

P. Dimopoulos, Dr. sc-techn., Empa,

Swiss Federal Laboratories for Materials Testing and

Research, Laboratory for I.C. Engines,

Ueberlandstrasse 129

$\mathrm{CH}-8600$ Duebendorf, Switzerland,

Tel.: +41-44-8234337, Fax: +41-44-8234041,

email: panayotis.dimopoulos@empa.ch

\section{DEFINITIONS, ACRONYMS, ABBREVIATIONS}

\begin{tabular}{|c|c|}
\hline \multicolumn{2}{|c|}{ Abbreviations } \\
\hline bmep & Brake mean effective pressure \\
\hline bsfc & Brake specific fuel consumption \\
\hline CNG & Compressed Natural Gas \\
\hline CR & Compression ratio \\
\hline $\mathrm{CR}_{\varphi}$ & Volume ratio at crank angle $\varphi$ \\
\hline DoE & Design of Experiments \\
\hline ECU & Engine Electronic Control Unit \\
\hline EGR & Exhaust gas recirculation rate \\
\hline EVO & Exhaust Valve Opening \\
\hline imep & Mean indicated pressure \\
\hline IVC & Inlet Valve Closing \\
\hline MFB & Mass Fraction Burned \\
\hline MFBx & $\begin{array}{l}\text { Duration for burning } \mathrm{x} \% \text { of the } \\
\text { cylinder mass }\end{array}$ \\
\hline SI & Spark Ignition \\
\hline ST & Spark Timing \\
\hline TDC & Top dead Center \\
\hline THC & Total unburned hydrocarbons \\
\hline TWC & Three way catalyst \\
\hline \multicolumn{2}{|c|}{ Latin characters } \\
\hline $\mathrm{B}$ & Engine bore dimensions \\
\hline$s_{p}$ & Mean piston speed \\
\hline$m_{f}$ & $\begin{array}{l}\text { Fuel mass introduced in the } \\
\text { cylinder per engine stroke }\end{array}$ \\
\hline$p_{c y l}$ & Cylinder pressure \\
\hline$p_{\mathrm{mi}}$ & Mean indicated pressure \\
\hline$p_{m i, g x}$ & $\begin{array}{l}\text { Break mean indicated pressure } \\
\text { through gas exchange }\end{array}$ \\
\hline $\mathrm{Q}_{\mathrm{b}}$ & $\begin{array}{l}\text { Combustion heat introduced by } \\
\text { the fuel }\end{array}$ \\
\hline$Q_{i c}$ & $\begin{array}{l}\text { Incomplete combustion heat } \\
\text { losses }\end{array}$ \\
\hline$Q_{L H V}$ & Lower heating value of the fuel \\
\hline $\mathrm{Q}_{\mathrm{rc}}$ & Real combustion heat losses \\
\hline$Q_{r g-b b}$ & Real gas and Blow-by losses \\
\hline $\mathrm{Q}_{\mathrm{wh}}$ & Cylinder wall heat losses \\
\hline $\mathrm{r}_{\mathrm{CV}, \varphi}$ & Constant volume Ratio \\
\hline $\mathrm{T}_{\text {cyl }}$ & Cylinder Temperature \\
\hline $\mathrm{V}$ & Cylinder volume \\
\hline $\mathrm{V}_{\mathrm{d}}$ & Cylinder displacement volume \\
\hline$W_{g x}$ & Gas exchange work \\
\hline \multicolumn{2}{|l|}{$\begin{array}{l}\text { Greek } \\
\text { characters }\end{array}$} \\
\hline$\alpha_{w}$ & $\begin{array}{l}\text { Heat transfer coefficient, cylin- } \\
\text { der gas to walls }\end{array}$ \\
\hline$\beta_{\mathrm{i}}$ & $\begin{array}{l}\text { Regression coefficients for the } \\
\text { DoE modelling }\end{array}$ \\
\hline Y & $\begin{array}{l}\text { Ratio of the specific heats of the } \\
\text { working fluid }\end{array}$ \\
\hline$\eta_{\mathrm{cv}}$ & $\begin{array}{l}\text { Fuel conversion efficiency of the } \\
\text { constant volume process }\end{array}$ \\
\hline$\eta_{f}$ & $\begin{array}{l}\text { Effective fuel conversion effi- } \\
\text { ciency }\end{array}$ \\
\hline
\end{tabular}

